\title{
Peripartum Cardiomyopathy Treatment with Dopamine Agonist and Subsequent Pregnancy with a Satisfactory Outcome
}

\section{Tratamento da miocardiopatia periparto com agonista dopaminérgico e subsequente gestação com resultado satisfatório}

\author{
Maria Adélia Medeiros e Melo ${ }^{1}$ Jordão Sousa Carvalho ${ }^{1}$ Francisco Edson de Lucena Feitosa ${ }^{1}$ \\ Edward Araujo Júnior ${ }^{2}$ Alberto Borges Peixoto ${ }^{2}$ Francisco Herlânio Costa Carvalho ${ }^{1}$ \\ Regina Coeli Marques Carvalho ${ }^{1}$
}

${ }^{1}$ Fetal Medicine Service, Maternidade-Escola Assis Chateaubriand, Universidade Federal do Ceará, Fortaleza, CE, Brazil

2 Department of Obstetrics, Escola Paulista de Medicina, Universidade Federal de São Paulo, São Paulo, SP, Brazil

Rev Bras Ginecol Obstet 2016;38:308-313.

\begin{abstract}
Keywords

- peripartum cardiomyopathy

- congestive heart failure

- dopamine agonists

- pregnancy outcome

Pathophysiological mechanisms of peripartum cardiomyopathy are not yet completely defined, although there is a strong association with various factors that are already known, including pre-eclampsia. Peripartum cardiomyopathy treatment follows the same recommendations as heart failure with systolic dysfunction. Clinical and experimental studies suggest that products of prolactin degradation can induce this cardiomyopathy. The pharmacological suppression of prolactin production by D2 dopamine receptor agonists bromocriptine and cabergoline has demonstrated satisfactory results in the therapeutic response to the treatment. Here we present a case of an adolescent patient in her first gestation with peripartum cardiomyopathy that evolved to the normalized left ventricular function after cabergoline administration, which was used as an adjuvant in cardiac dysfunction treatment. Subsequently, despite a short interval between pregnancies, the patient exhibited satisfactory progress throughout the entire gestation or puerperium in a new pregnancy without any cardiac alterations. Dopamine agonists that are orally used and are affordable in most tertiary centers, particularly in developing countries, should be considered when treating peripartum cardiomyopathy cases.
\end{abstract}

received January 16, 2016 accepted May 3, 2016
DOI http://dx.doi.org/ 10.1055/s-0036-1584567. ISSN 0100-7203.
Copyright $\odot 2016$ by Thieme Publicações License terms Ltda, Rio de Janeiro, Brazil

(c) $(1) \$$ 


\section{Resumo}
Palavras-chave
- miocardiopatia periparto
- falência cardíaca congestiva
- agonistas dopaminérgicos
- resultado da gravidez

Os mecanismos fisiopatológicos da miocardiopatia periparto ainda não são totalmente definidos, apesar de haver forte associação com vários fatores já conhecidos, incluindo a pré-eclâmpsia. $\mathrm{O}$ tratamento segue as mesmas recomendações para a insuficiência cardíaca com disfunção sistólica. Estudos clínicos e experimentais recentes sugerem que os produtos de degradação da prolactina podem induzir a miocardiopatia. A supressão farmacológica da produção de prolactina por agonista do receptor D2 da dopamina, bromocriptina ou cabergolina, vem demonstrando resultados satisfatórios na resposta terapêutica do tratamento. Apresentamos o relato de uma primigesta, adolescente, com miocardiopatia periparto que evoluiu para a normalização da função ventricular esquerda após a administração da cabergolina, utilizada como adjuvante na terapêutica da disfunção cardíaca. Subsequentemente, apesar do intervalo entre as gestações ser considerado curto, apresentou evolução satisfatória em uma nova gestação sem qualquer alteração cardíaca durante todo o período gestacional ou puerpério. Os agonistas dopaminérgicos, drogas de uso oral e de preço acessível para a maioria dos centros terciários, em particular em países subdesenvolvidos, não podem ser esquecidos frente a casos de miocardiopatia periparto.

\section{Introduction}

Peripartum cardiomyopathy (PPCM) is a dilated cardiomyopathy that clinically manifests with systolic dysfunction of the left ventricle (LV) and ejection fraction (EF) of $<45 \%$. In the absence of other causes of heart failure, PPCM most often occurs at the end of pregnancy or in the months following childbirth, and it is, therefore a diagnosis of exclusion. ${ }^{1}$ The incidence of PPCM varies depending on the geographical area. The highest incidences of PPCM are found in studies from South Africa (1 in 1000) and Haiti (1 in 400). ${ }^{2,3}$ In the United States, it is estimated that PPCM incidence is 1 case for every 3200 live births, ${ }^{4,5}$ and the disease more frequently occurs in African-American women. ${ }^{6,7}$

Pathophysiological mechanisms of PPCM remain unclear, although there is a strong association with several wellknown factors, such as malnutrition, poor selenium intake, multiparity, multiple pregnancies, advanced maternal age (> 35 years), viral myocarditis, autoimmune response, genetic susceptibility, and, more recently, association with preeclampsia. ${ }^{8-11}$

PPCM treatment follows the same recommendations as heart failure with systolic dysfunction; the treatment includes angiotensin-converting enzyme (ACE) inhibitors, $\beta$ blockers, systemic vasodilators, and diuretics, which improve symptoms. In some cases, prognosis remains uncertain, with mortality rates varying from 4 to $30 \%^{8,12,13}$ Recovery of myocardial function occurs in only $23-32 \%$ of PPCM cases, and $25 \%$ of cases evolve into the progressive deterioration of the disease, in which only cardiac transplant remains as the last recourse for patient survival. ${ }^{5,14,15}$

Clinical and experimental studies suggest that the products of prolactin degradation can induce PPCM. ${ }^{15-20}$ The increase in oxidative stress during pregnancy may trigger the activation of proteinase cathepsin $\mathrm{D}$, which cleaves the 23-kDa molecular weight prolactin into smaller fragments, generating a $16-\mathrm{kDa}$ prolactin subfragment. This prolactin subfragment causes an angiogenic imbalance with the breaking down of capillaries and endothelial damage, along with inhibiting vasodilatory factors, such as nitric oxide, culminating in damaging cardiomyocytes, dilating cardiac chambers, and consequent myocardial dysfunction. The pharmacological suppression of prolactin production by agonist of D2 dopamine receptor, bromocriptine or cabergoline has demonstrated satisfactory results in the therapeutic response to PPCM treatment. ${ }^{17,21-23}$

Here we present a case of a pregnant woman with PPCM who progressed into the normalization of the left ventricular function after being administered cabergoline, and who subsequently presented a satisfactory progress throughout the entire gestation or puerperium in a new pregnancy without exhibiting any cardiac alterations.

\section{Case Report}

A 16-year old mixed-race female, who was in her first pregnancy with a gestational age of 36 weeks and 4 days that was estimated by the date of her last menstrual period, was admitted to the emergency ward of the MaternidadeEscola Assis Chateaubriand. She reported that 24 hours prior to that, she sought care at an emergency obstetrics clinic with complaints of dyspnea, cough with hemoptoic sputum and fever. She had no history of heart disease or any similar clinical condition. According to the referral report, at the time of examination, her blood pressure (BP) was 160/ $120 \mathrm{~mm} \mathrm{Hg}$; thus, hydralazine was intravenously administered (a total of $20 \mathrm{mg}$ ) along with magnesium sulfate to treat the clinical suspicion of severe pre-eclampsia.

At the time of admission, the patient exhibited tachypnea with a respiratory rate of 28 breaths/min, temperature of $37.2^{\circ} \mathrm{C}$, and BP of $130 / 80 \mathrm{~mm} \mathrm{Hg}$. Pulmonary auscultation revealed reduced breath sounds at the bases of the lungs, particularly on the right side, with the presence of crackling 


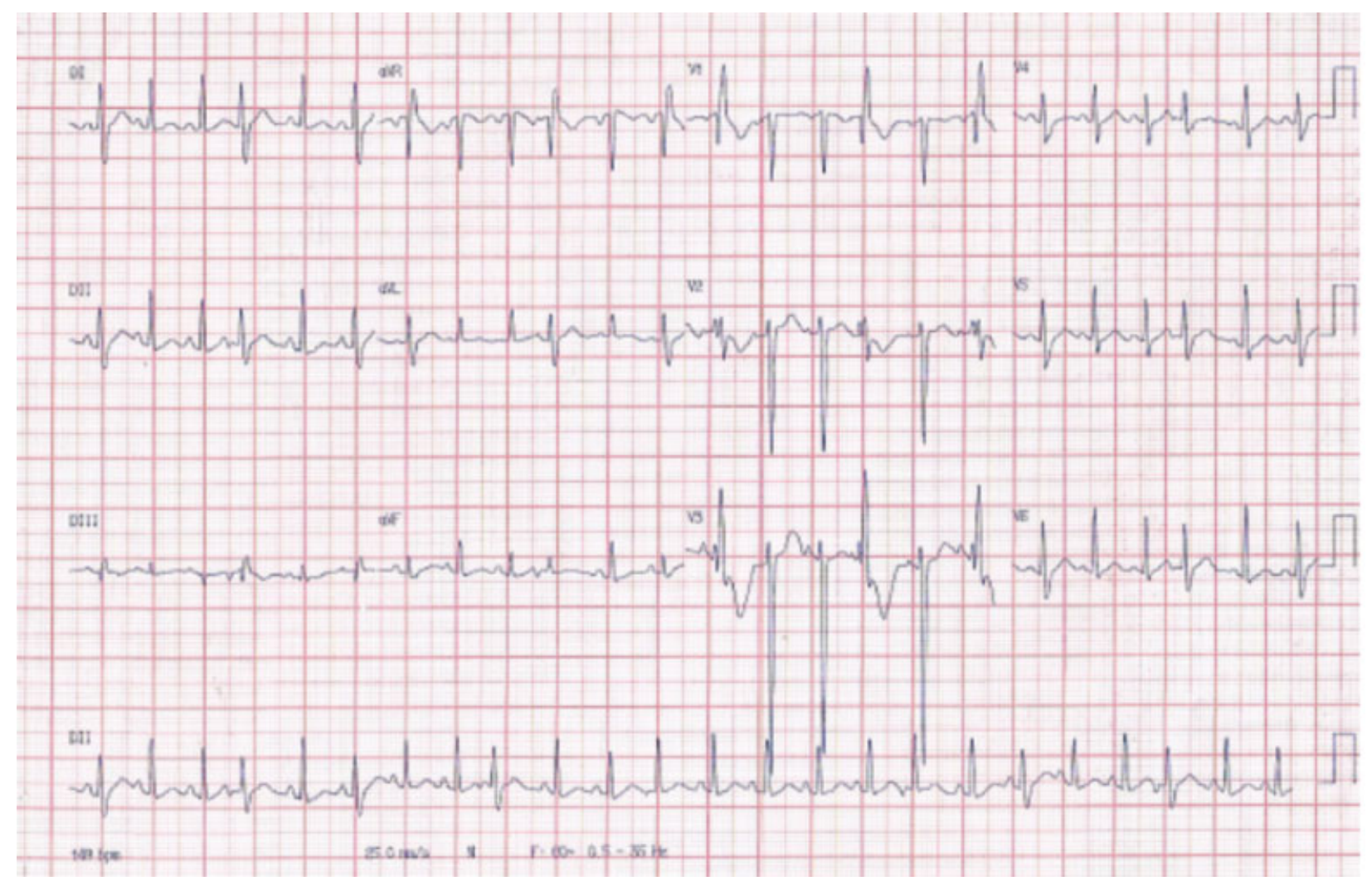

Fig. 1 Electrocardiogram taken on admission showing sinus tachycardia.

rales. Cardiac auscultation revealed regular heart rhythm without murmurs and a heart rate (HR) of $132 \mathrm{bpm}$. Obstetric examination revealed a gravid uterus that was compatible with the gestational age, and fetal heartbeat was $154 \mathrm{bpm}$. Electrocardiogram (ECG) revealed sinus tachycardia (-Fig. 1). Laboratory test results were as follows: hemoglobin $(\mathrm{Hb}), 9.5 \mathrm{~g} / \mathrm{dL}$; hematocrit $(\mathrm{Ht}), 30.3 \%$; platelet count, $314,000 / \mathrm{mm}^{3}$; urea, $35 \mathrm{mg} / \mathrm{dL}$; creatinine, $1.4 \mathrm{mg} / \mathrm{dL}$; sodium, $132 \mathrm{mmol} / \mathrm{L}$; potassium, $2.9 \mathrm{mmol} / \mathrm{L}$; magnesium, 3.7 $\mathrm{mg} / \mathrm{L}$; chloride, $101 \mathrm{mmol} / \mathrm{L}$; alanine aminotransferase, 2.0 $\mathrm{U} / \mathrm{L}$; aspartate aminotransferase, $12 \mathrm{U} / \mathrm{L}$; total bilirubin, 2.37 $\mathrm{mg} / \mathrm{dL}$; direct bilirubin, $1.97 \mathrm{mg} / \mathrm{dL}$; indirect bilirubin, 0.4 $\mathrm{mg} / \mathrm{dL}$; and uric acid, $6.2 \mathrm{mg} / \mathrm{dL}$. Test results of arterial blood gases were $\mathrm{pH}, 7.2 ; \mathrm{pCO}_{2}, 44.1 \mathrm{~mm} \mathrm{Hg} ; \mathrm{pO}_{2}, 411.21 \mathrm{~mm} \mathrm{Hg}$; $\mathrm{BE},-7.3$; anion gap, $10.3 \mathrm{mmol} / \mathrm{L}$; glutamate, $130 \mathrm{mg} / \mathrm{dL}$; and lactate, 1.37 .

With respect to the clinical data and laboratory tests, a diagnosis of severe pre-eclampsia with acute pulmonary edema was made, and the interruption of gestation via abdominal delivery under general anesthesia was indicated along with posterior investigation of possible maternal cardiopathy.

In the immediate postoperative period, the patient was transferred to the intensive care unit (ICU). When admitted to the ICU, the patient was still on mechanical ventilation (MV), with $50 \%$ fraction of inspired oxygen with a sedation of 03 on the Ramsey scale. Overall, the patient's condition was compromised; she was afebrile, with HR of $128 \mathrm{bpm}$, BP of $94 / 56 \mathrm{~mm} \mathrm{Hg}$, and mean arterial pressure of $68 \mathrm{~mm} \mathrm{Hg}$.
Heartbeat was regular over three periods, with the third heart sound present.

The patient remained sedated and was administered a maintenance dose for sulfate therapy. A chest X-ray was taken, demonstrating lung congestion and increased cardiothoracic ratio ( - Fig. 2). ECG revealed sinus tachycardia, HR of $100 \mathrm{bpm}$, and $600^{\circ}$ axis, with a slow R-wave progression from

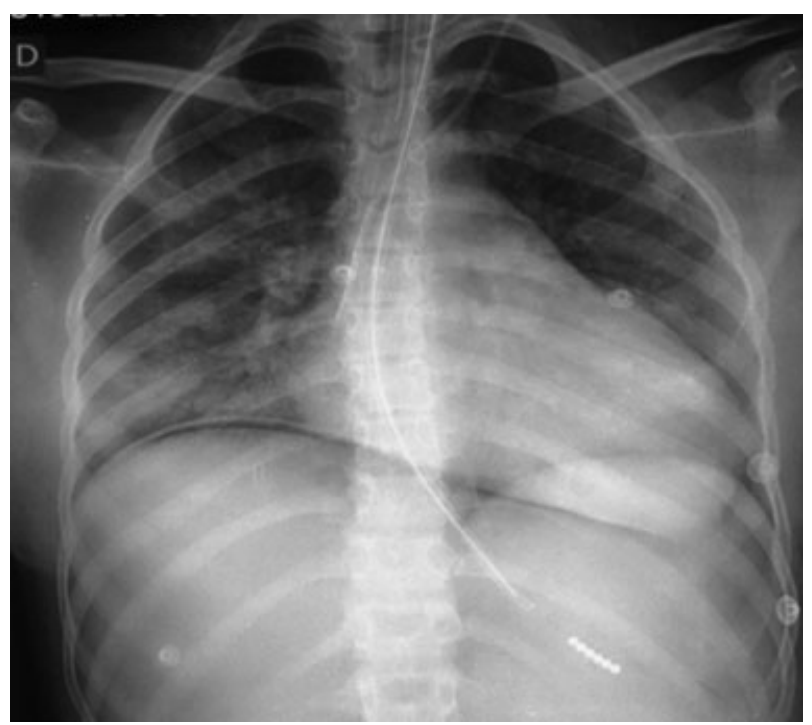

Fig. 2 Anteroposterior chest X-rays showing slight increase in cardiothoracic ratio. 


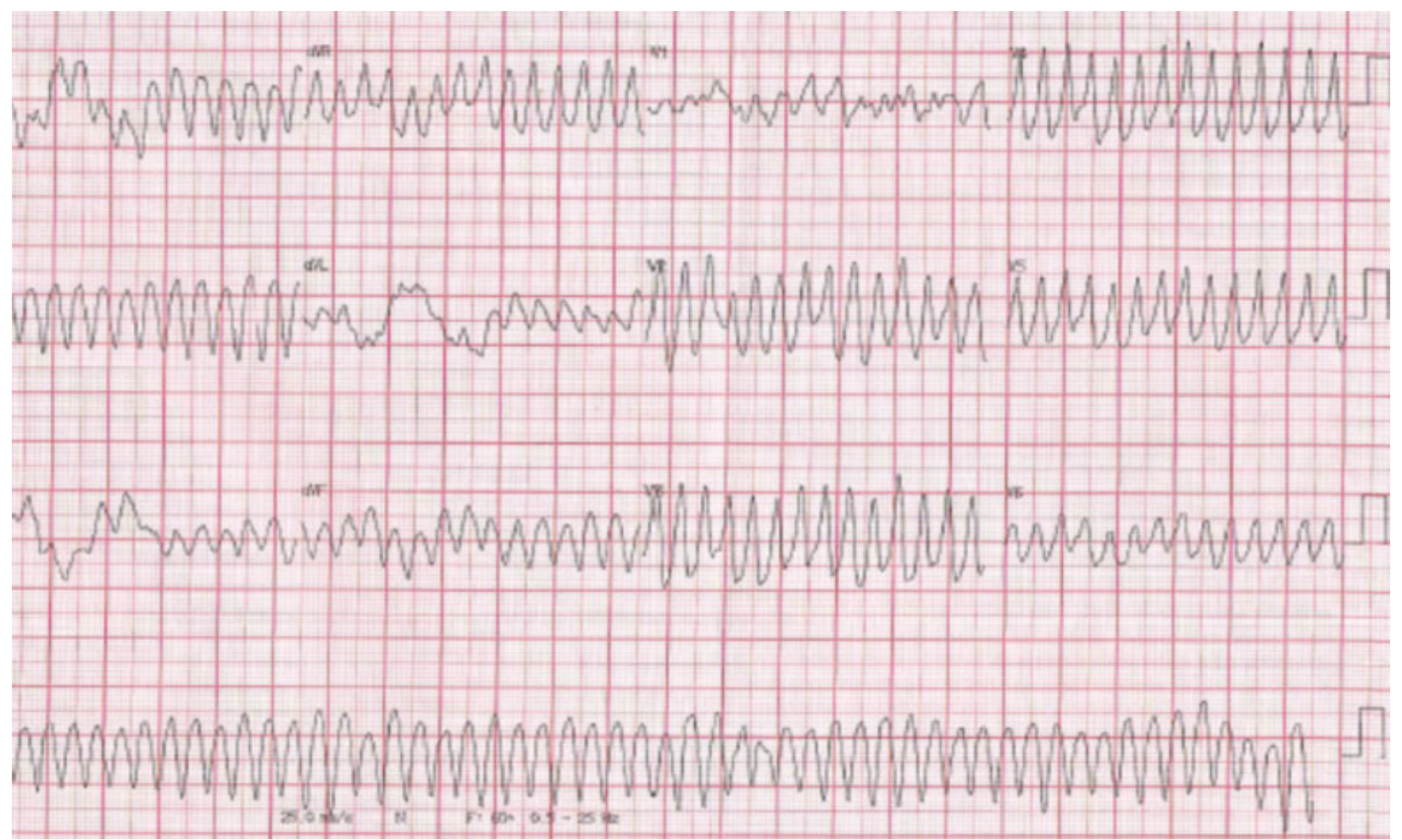

Fig. 3 Electrocardiogram showing sustained ventricular tachycardia.

V1 to V4; transthoracic Doppler echocardiogram revealed the presence of a diffuse hypokinesia, systolic dysfunction, and left ventricular ejection fraction (LVEF) of $40 \%$. With this additional data, continuous infusion of furosemide, $5 \mathrm{mcg} /$ $\mathrm{kg} / \mathrm{min}$ dobutamine, and $10 \mathrm{mcg} / \mathrm{min}$ nitroglycerin was initiated.

On the 3rd day of hospitalization, the patient remained on MV and exhibited fever spikes $\left(39.5^{\circ} \mathrm{C}\right)$ that were accompanied with thick yellow secretions from the airways; subsequently, antibiotic therapy was initiated with piperacillin sodium and tazobactam sodium. After therapy, laboratory test results were as follows: $\mathrm{Hb}, 7.3 \mathrm{~g} / \mathrm{dL}$; $\mathrm{Ht}, 23.7 \%$; platelet count, $372,000 / \mathrm{mm}^{3}$; urea, $39 \mathrm{mg} / \mathrm{dL}$; creatinine, $1.0 \mathrm{mg} / \mathrm{dL}$; sodium, $156 \mathrm{mmol} / \mathrm{L}$; potassium, $4.0 \mathrm{mmol} / \mathrm{L}$; and magnesium, $1.9 \mathrm{mg} / \mathrm{L}$. The patient suddenly exhibited severe ventricular arrhythmia with several episodes of sustained ventricular tachycardia (SVT), which satisfactorily responded to an intravenous administration of $300 \mathrm{mg}$ amiodarone (-Fig. 3). Despite continuing $5 \mathrm{mcg} / \mathrm{kg} / \mathrm{min}$ amiodarone, ventricular arrhythmia persisted with several repeated episodes of non-SVT, which only returned to a sinus rhythm after an intravenous administration of $2 \%(1 \mathrm{mg} / \mathrm{kg}$ ) lidocaine that was maintained at $4 \mathrm{mg} / \mathrm{kg} / \mathrm{min}$ for 72 hours.

Another transthoracic Doppler echocardiogram was performed on the 11th day of hospitalization and revealed similar findings to the previous examination (LVEF of $40 \%$ ); however, the chest X-ray demonstrated improvement in lung congestion. On the 13th day of hospitalization, the patient's clinical condition had sufficiently improved to indicate removal from MV. However, this was unsuccessful because the patient presented laryngeal stridor and required re-intubation followed by tracheostomy. On the 25th day, the patient was successfully weaned off tracheostomy and was transferred to the ward with the following medications: $0.125 \mathrm{mg} /$ day digoxin, $40 \mathrm{mg} /$ day furosemide, $12.5 \mathrm{mg} /$ day carvedilol, $75 \mathrm{mg} /$ day captopril, and $25 \mathrm{mg} /$ day spironolactone.

In the ward, the patient reported generalized weakness, dyspnea at minimum exertion, and restriction to bed (New York Heart Association functional class III-IV). The patient again presented a productive cough and fever, and during a physical therapy session, she complained of malaise, dizziness, hypotension (BP, 67/32 mm Hg) and irregular pulse (122 bpm), and was again transferred to the ICU. Upon re-admission to the ICU, the patient was conscious, febrile, cooperative, eupneic, 15 on the Glasgow scale, spontaneously breathing without oxygen support, had an oxygen saturation of $99 \%$, a breathing rate of 28 breaths/min, BP of $88 / 60 \mathrm{~mm} \mathrm{Hg}$, and capillary glucose level of $139 \mathrm{mg} / \mathrm{dL}$. ECG revealed sinus rhythm with the presence of supraventricular extrasystoles. The patient remained in the ICU for another 56 hours, and on the 33rd day of hospitalization she was transferred back to the ward, and antibiotics Tazocin ${ }^{\mathrm{TM}}$ and teicoplanin were added to her medication. On the 37th day, the patient underwent another transthoracic Doppler echocardiogram that revealed worsening of LVEF (37\%) and diffuse hypokinesia, without a significant increase in intracavity diameters, moderate contractile deficits, moderate systolic dysfunctions, and mild diastolic dysfunctions of LV (Stage I) (-Fig. 4). On the 39th day, the patient continued in the functional class III-IV without clinical improvement, despite optimized therapy for systolic heart failure. For studies report improved peripartum cardiomyopathy 


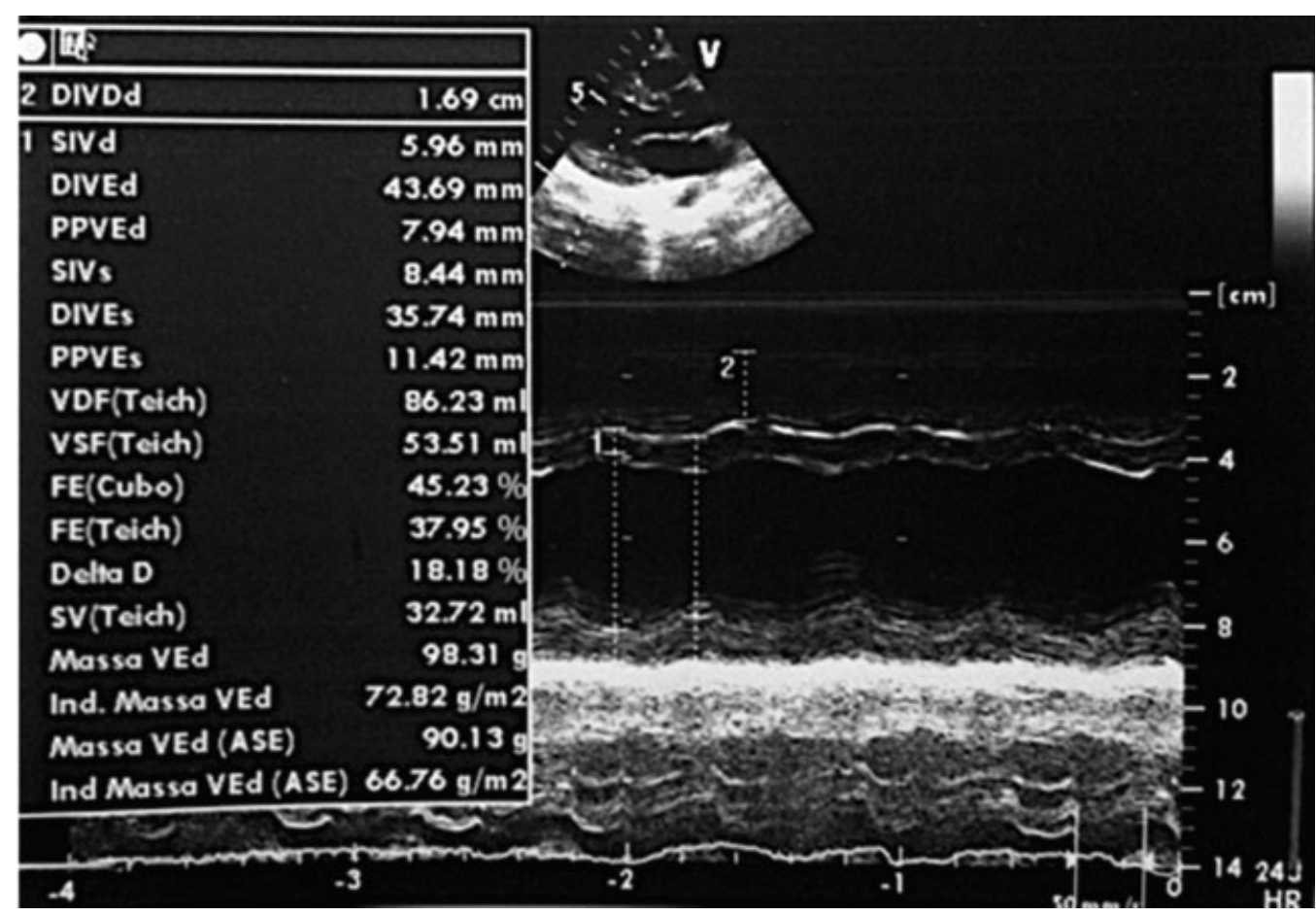

Fig. 4 Transthoracic Doppler echocardiogram showing ejection fraction of $37 \%$.

with inhibitor of prolactin secretion was decided in a joint evaluation with an obstetrician and cardiologist prescribe cabergoline $1 \mathrm{mg}$ once a week, there were two doses. After the third day of the first dose of drug, the patient presented significant clinical improvement, and as symptoms decreased and functional capacity improved, digoxin and furosemide were discontinued. On the 9th day after the first cabergoline administration, a thoracic X-ray was performed, which revealed a reduction in the cardiac area. A new transthoracic Doppler echocardiogram revealed the right ventricle with preserved contractility and improvement in the systolic dysfunction with an EF of $43 \%$, but with continuing diffuse hypokinesia and moderate systolic dysfunction and left ventricular relaxation deficit. Despite clinical improvements, the third and last weekly dose of cabergoline was administered.

The patient was discharged without symptoms, and had progressive improvement in functional capacity by taking $6.25 \mathrm{mg}$ carvedilol every 12 hours and $25 \mathrm{mg} /$ day spironolactone. Ninety days after hospital discharge, the currently completely asymptomatic patient reported delayed menstruation and had positive $\beta$-HCG results. Transvaginal ultrasound confirmed a single pregnancy at 9 weeks and 6 days. Transthoracic Doppler echocardiogram revealed an EF of $73 \%$, cavities with normal dimensions and wall thickness, normal heart valves, preserved contractility, normal systolic function in both ventricles, normal pericardial leaflets, and an ECG in sinus rhythm without changes. The use of all medications was suspended.

The second pregnancy progressed without any clinical complications to the fetus or mother. During examinations at the end of pregnancy, the patient continued to have a normal ECG and a LVEF of 70\%. The baby was abdominally delivered without complications, and the patient was discharged after 48 hours.

\section{Discussion}

PPCM remains a diagnosis of exclusion, with no specific treatment and uncertain prognosis. National and international records, whether systematic or collected from clinical cases, are required to better understand this disease. Multicenter studies are also required to improve the understanding of the pathogenic mechanisms of PPCM, including its genetic potential, sociocultural aspects involved in its development, and its association with cardiovascular comorbidities and, more recently, with pre-eclampsia. ${ }^{9}$

Currently, PPCM treatment follows the same guidelines provided for dilated cardiomyopathy; the treatment includes drug therapy with ACE inhibitors, $\beta$-blockers, vasodilators and diuretics. However, there is no specific therapy for this disease. ${ }^{12,17}$ Haghikia et al $^{24}$ established a prospective registry with confirmed PPCM present in 115 patients (mean baseline LVEF: $27 \pm 9 \%$ ). Follow-up data ( $6 \pm 3$ months) showed LVEF improvement in $85 \%$ and full recovery in $47 \%$, while $15 \%$ failed to recover, with death in $2 \%$ of patients. A high recovery rate (96\%) was observed in patients obtaining combination therapy with $\beta$-blockers, angiotensin-converting enzyme (ACE) inhibitors/angiotensin-receptorblockers (ARBs) and bromocriptine.

PPCM prognosis depends on the degree that the LV is affected and the recoverability of the myocardium. Mortality rates of PPCM vary from $18 \%$ to $60 \%{ }^{4}$ however, there are reports from Africa that progressive myocardial deterioration occurs in $50 \%$ of cases despite optimized therapy for 
heart failure, and heart transplant is the only option for patient survival. $^{1,10-13}$

Recent clinical and experimental findings describe a common mechanism in the development of PPCM: the increase in gestational period-related oxidative stress may be involved in PPCM pathogenesis. The activation of enzymes, such as metalloproteinase and cathepsin resulting from oxidative stress, in cardiomyocytes cleaves the 23-kDa molecular weight prolactin into smaller $16-\mathrm{kDa}$ fragments. These 16-kDa fragments are angiostatic and pro-inflammatory factors, and are involved in the apoptosis of cardiomyocytes and, subsequently, the dilation of the heart chambers and myocardial dysfunction. ${ }^{15-20}$

The suppression of prolactin production by D2 dopamine receptor agonists bromocriptine and cabergoline represents a new therapeutic approach in PPCM and could change the course of PPCM and decrease maternal morbidity and mortality associated with this disease. Few cases have been reported that describe the use of dopamine agonists in patients with PPCM; however, they report a more rapid improvement in ventricular function with the use of both drugs. ${ }^{17,21-23}$ Experimental studies, particularly randomized clinical trials, in the coming years are likely to yield more data regarding the real advantages of the use of dopaminergic agonists as adjuvants in the treatment of similar cases. They also may indicate whether there are clinical differences between bromocriptine and cabergoline.

We sought to describe another case of satisfactory progress with the use of a dopaminergic agonist, which is a drug orally used and affordable in most reference centers, particularly in developing countries. It is easy to use; thus, it should be considered as an adjuvant to the other therapeutic options when treating PPCM cases for faster recovery of ventricular function.

In particular, this case was the first to demonstrate satisfactory progress in a subsequent gestation. Despite the short interval between pregnancies, this case may also suggest more satisfactory long-term progress.

\section{References}

1 Sliwa K, Hilfiker-Kleiner D, Petrie MC, et al; Heart Failure Association of the European Society of Cardiology Working Group on Peripartum Cardiomyopathy. Current state of knowledge on aetiology, diagnosis, management, and therapy of peripartum cardiomyopathy: a position statement from the Heart Failure Association of the European Society of Cardiology Working Group on peripartum cardiomyopathy. Eur J Heart Fail 2010;12(8):767-778

2 Hilfiker-Kleiner D, Sliwa K. Pathophysiology and epidemiology of peripartum cardiomyopathy. Nat Rev Cardiol 2014;11(6):364-370

3 Fett JD, Carraway RD, Dowell DL, King ME, Pierre R. Peripartum cardiomyopathy in the Hospital Albert Schweitzer District of Haiti. Am J Obstet Gynecol 2002;186(5):1005-1010

4 Elkayam U. Clinical characteristics of peripartum cardiomyopathy in the United States: diagnosis, prognosis, and management. J Am Coll Cardiol 2011;58(7):659-670

5 McNamara DM, Elkayam U, Alharethi R, et al; IPAC Investigators. Clinical outcomes for peripartum cardiomyopathy in North
America: results of the IPAC Study (Investigations of Pregnancy-Associated Cardiomyopathy). J Am Coll Cardiol 2015;66(8): 905-914

6 Gentry MB, Dias JK, Luis A, Patel R, Thornton J, Reed GL. AfricanAmerican women have a higher risk for developing peripartum cardiomyopathy. J Am Coll Cardiol 2010;55(7):654-659

7 Goland S, Modi K, Hatamizadeh P, Elkayam U. Differences in clinical profile of African-American women with peripartum cardiomyopathy in the United States. J Card Fail 2013;19(4): 214-218

8 Pearson GD, Veille JC, Rahimtoola S, et al. Peripartum cardiomyopathy: National Heart, Lung, and Blood Institute and Office of Rare Diseases (National Institutes of Health) workshop recommendations and review. JAMA 2000;283(9):1183-1188

9 Bello N, Rendon IS, Arany Z. The relationship between preeclampsia and peripartum cardiomyopathy: a systematic review and meta-analysis. J Am Coll Cardiol 2013;62(18): $1715-1723$

10 Johnson-Coyle L, Jensen L, Sobey A; American College of Cardiology Foundation; American Heart Association. Peripartum cardiomyopathy: review and practice guidelines. Am J Crit Care 2012; 21(2):89-98

11 Blauwet LA, Cooper LT. Diagnosis and management of peripartum cardiomyopathy. Heart 2011;97(23):1970-1981

12 Sliwa K, Fett J, Elkayam U. Peripartum cardiomyopathy. Lancet 2006;368(9536):687-693

13 Ramaraj R, Sorrell VL. Peripartum cardiomyopathy: Causes, diagnosis, and treatment. Cleve Clin J Med 2009;76(5):289-296

14 Rasmusson K, Brunisholz K, Budge D, et al. Peripartum cardiomyopathy: post-transplant outcomes from the United Network for Organ Sharing Database. J Heart Lung Transplant 2012;31(2): 180-186

15 Biteker M, Kayatas K, Duman D, Turkmen M, Bozkurt B. Peripartum cardiomyopathy: current state of knowledge, new developments and future directions. Curr Cardiol Rev 2014;10(4): 317-326

16 Hilfiker-Kleiner D, Sliwa K, Drexler H. Peripartum cardiomyopathy: recent insights in its pathophysiology. Trends Cardiovasc Med 2008;18(5):173-179

17 Yamac H, Bultmann I, Sliwa K, Hilfiker-Kleiner D. Prolactin: a new therapeutic target in peripartum cardiomyopathy. Heart 2010; 96(17):1352-1357

18 Gonzalez C, Corbacho AM, Eiserich JP, et al. 16K-prolactin inhibits activation of endothelial nitric oxide synthase, intracellular calcium mobilization, and endothelium-dependent vasorelaxation. Endocrinology 2004;145(12):5714-5722

19 Hilfiker-Kleiner D, Kaminski K, Podewski E, et al. A cathepsin D-cleaved $16 \mathrm{kDa}$ form of prolactin mediates postpartum cardiomyopathy. Cell 2007;128(3):589-600

20 Patten IS, Rana S, Shahul S, et al. Cardiac angiogenic imbalance leads to peripartum cardiomyopathy. Nature 2012;485(7398): 333-338

21 Jahns BG, Stein W, Hilfiker-Kleiner D, Pieske B, Emons G. Peripartum cardiomyopathy-a new treatment option by inhibition of prolactin secretion. Am J Obstet Gynecol 2008;199(4):e5-e6

22 Sliwa K, Blauwet L, Tibazarwa K, et al. Evaluation of bromocriptine in the treatment of acute severe peripartum cardiomyopathy: a proofof-concept pilot study. Circulation 2010;121(13):1465-1473

23 de Jong JS, Rietveld K, van Lochem LT, Bouma BJ. Rapid left ventricular recovery after cabergoline treatment in a patient with peripartum cardiomyopathy. Eur J Heart Fail 2009;11(2):220-222

24 Haghikia A, Podewski E, Libhaber E, et al. Phenotyping and outcome on contemporary management in a German cohort of patients with peripartum cardiomyopathy. Basic Res Cardiol 2013;108(4):366 